\title{
Formation of Particles in Sol-Gel Process
}

\author{
Sumio Sakka \\ Institute for Chemical Research \\ Kyoto University*
}

\begin{abstract}
The formation of particles in starting solutions and its significance for the sol-gel processing of oxide materials are reviewed on the basis of previous works including our work. First, hydrolysis and polycondensation reactions of metal alkoxides in alcohol-water solutions are briefly discussed. Then, it is shown that powders prepared by the sol-gel method using metal alkoxides are suitable as starting powders for high performance glasses and ceramics because the particles produced are fine, monodispersed and uniform in chemical composition. It is also shown that the formation of round-shaped particles larger than, say, $10 \mathrm{~nm}$ in sols may lead to porous silica monoliths of plate or rod shape without occurrence of cracks during drying of the wet gel. It should be noted that crack-free gel monoliths can be sintered to monoliths of glass and ceramics. It is shown that essentially one-dimensional longshaped particles can be produced by adjusting the composition and conditions of processing of the starting solution, which is required for fiber drawing from viscous sols in the course of sol-to-gel conversion.
\end{abstract}

\section{Introduction}

In the sol-gel process ${ }^{1 \sim 5)}$, formation of fine oxide particles takes place in sols. In some cases, particles formed in a sol are collected as a powder and formed into a powder compact for further processing, for example, sintering. Although gelation of the whole sol does not occur in this case, one might be permitted to call the process a "sol-gel method", because the individual powder particles may be gel-like. In other sol-gel processes, sols with suspended particles are formed into monoliths, fibers and coating films of gel in the course of the transformation of fluid and viscous sols to solidified gels. Such processes may be called typical solgel process.

In all those cases, particles with controlled size, size distribution and shape can be formed in the sol, which is essential for subsequent processing, such as sintering of the power compact and formation of various shapes in the course of sol-to-gel transition.

* Gokasho, Uji-shi, Kyoto-fu, 611

TEL. 0774-32-5428

Received May, 20, 1989
In this paper, previous works on the formation of particles in the sol have been reviewed with special attention given to the effect of particle size and shapes on the formability of the sol and sintering of a gel to ceramics or glass.

The advantages of the sol-gel method are most conspicuously displayed when metal alkoxides are utilized as starting compounds. This paper deals, therefore, mainly with sol-gel methods using metal alkoxides. Also, silica will be the main oxide species discussed here.

\section{Reactions of metal alkoxides in sols leading to particle formation}

Usually, the sol-gel method starts with a solution containing metal alkoxide, water and alcohol. A small amount of acid or ammonia is added as a catalyst, in order to adjust the reaction of particle formation or to promote the gelling reaction of the solution. A metal alkoxide ${ }^{6,7)}, \mathrm{M}(\mathrm{OR})$, where $\mathrm{M}$ is a metal atom, $\mathrm{R}$ is an alkyl group and $n$ is the valence of $\mathrm{M}$, is first partially hydrolyzed by water or totally as shown by the formula,

$$
\begin{aligned}
\mathrm{M}(\mathrm{OR})_{n}+x \mathrm{H}_{2} \mathrm{O} & \rightarrow \mathrm{M}(\mathrm{OH})_{x}(\mathrm{OR})_{n-x}+x \mathrm{ROH} \\
x & \leqq n
\end{aligned}
$$


withe value $x$, which shows the degree of hydrolysis of each metal alkoxide molecule in sol, depends on the type of metal, the content of water in the solution, the kind of catalyst, and the relative rates of hydrolysis and polycondensation. The hydrolysis of alkoxyl groups OR to hydroxyl groups $\mathrm{OH}$ is accompanied by a condensation reaction, as shown by the formulae,

$$
\begin{aligned}
& -\mathrm{M}-\mathrm{OH}+\mathrm{H}-\mathrm{O}-\mathrm{M} \rightarrow-\mathrm{M}-\mathrm{O}-\mathrm{M}-+\mathrm{H}_{2} \mathrm{O} \\
& \text { Condensation by dehydration } \\
& -\mathrm{M}-\mathrm{OH}+\mathrm{R}-\mathrm{O}-\mathrm{M} \rightarrow-\mathrm{M}-\mathrm{O}-\mathrm{M}-+\mathrm{ROH} \\
& \text { Condensation by dealcoholization }
\end{aligned}
$$

As a result of polycondensation, particles consisting of metal-oxygen bondings may be produced.

The hydrolysis-polycondensation reactions are subject to the influence of many factors. Extensive studies have been made on the reactions of silicon alkoxides, but they are not fully understood yet. One can presume, however, that the growth of particles can be one-dimensional, leading to the formation of long-shaped particles when polycondensation takes place immediately after the hydrolysis of one or two OR groups of a molecule. The growth may be three-dimensional, leading to formation of round particles when polycondensation does not take place until all of the OR groups of a molecule are hydrolyzed to $\mathrm{OH}$ groups ${ }^{8)}$.

The growth of particles and the change in the aggregation state of primary particles take place in sols by the mechanism ${ }^{9,10)}$ illustrated in Fig. 1 and listed in Table 1. (1) in Fig. 1 shows that fine particles, that is, siloxane oligomers or polymers, grow as a result of condensation of the hydroxyl groups belonging to them. Ostwald ripening can take place after most of the hydrolyzed molecules are deposited on the particles. In Ostwald ripening, larger particles become larger at the expense of smaller particles, which may be dissolved due to higher activity and deposited on the larger particles, as shown in (2) of Fig. 1. Aggregation of particles may occur as a result of collision and bond formation at the contact point of particles. This results in loosely connected secondary particles, as shown in (3) of Fig. 1. When the secondary particles are connected infinitely as a network as shown in (4) of Fig. 1, it can be said that gelation has taken place. At this stage, if there is no water left and alcohol or other organic solvent is the only liquid, round particles remain without being firmly connected to each other until the gel is sintered by heating at

\begin{tabular}{|c|c|}
\hline Mechanism & Remark \\
\hline $\begin{array}{l}\text { (1) Reaction of a particle } \\
\text { with alkoxide molecules }\end{array}$ & $\begin{array}{l}\text { Simple growth of pri- } \\
\text { mary particles }\end{array}$ \\
\hline (2) Ostwald ripening & $\begin{array}{l}\text { Growth of larger parti- } \\
\text { cles }\end{array}$ \\
\hline $\begin{array}{l}\text { (3) Collision of one particle } \\
\text { with another }\end{array}$ & $\begin{array}{l}\text { Formation of second- } \\
\text { ary particles }\end{array}$ \\
\hline $\begin{array}{l}\text { (4) Association of secondary } \\
\text { particles }\end{array}$ & Network formation \\
\hline $\begin{array}{l}\text { (5) Neck formation by dis- } \\
\text { sociation and decom- } \\
\text { position }\end{array}$ & $\begin{array}{l}\text { Strong-bond formation } \\
\text { between particles }\end{array}$ \\
\hline
\end{tabular}
higher temperatures. If water remains at gela-

Table 1 Mechanisms of grow th and aggregation of particles 9,10 )

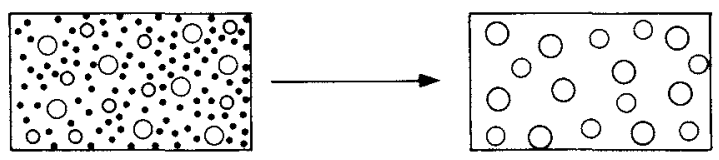

(1) Reaction with molecules

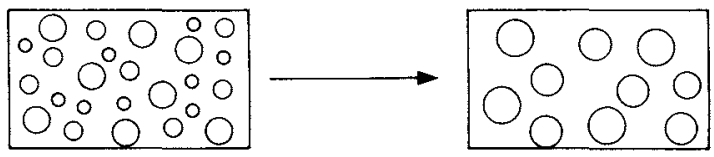

(2) Ostwald ripening

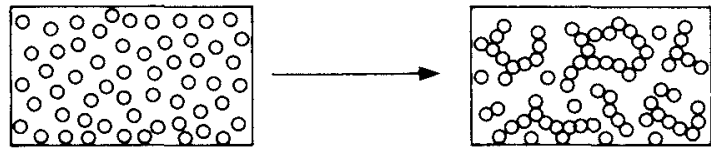

(3) Collision of particles

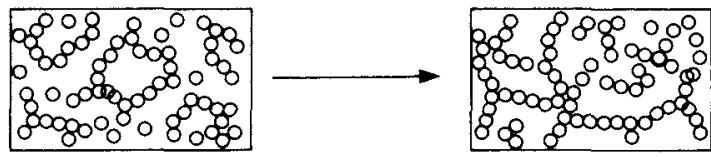

(4) Association of secondary particles

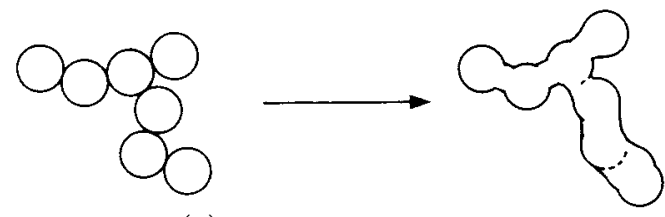

(5) Neck formation

Fig. 1 Growth, aggregation and network formation of particles in sols and gels 
tion, aging at temperatures lower than 100 $150^{\circ} \mathrm{C}$ causes round particles to be firmly connected as a result of the dissolution of oxide components, for example the silica component, at the surface of round particles and deposition of the component at the neck points, as shown in (5) of Fig. 1.

If compact aggregates are formed instead of loosely bound aggregates (4 in Fig. 1) in sols and they are separated from the solvent, precipitation may occur. The resultant precipitates are not usually suitable for further processing, because they are not fine particles, and they no longer show the characteristics of the particles made by the sol-gel method. For the sol-gel method, particles shown in left-hand side of (3) of Fig. 1 are suitable as starting powders for sintering, and gels shown in right-hand side of (4) of Fig. 1 are suitable for the formation of monoliths, which form dried porous plates and cylinders, or sintered glass or ceramic plates and cylinders.

When fibers are drawn from a viscous sol without passing through powder processing, the sol must contain polymers or one-dimensinal long particles.

3. Powders prepared by the sol-gel method for sintered ceramics

Generally, high performance polycrystalline ceramics have high mechanical strength and exhibit excellent functional properties when they are characterized by: (1) being well sintered, (2) dense texture without pores, (3) fine grains, (4) high purity, and (5) high uniformity in composition throughout the grains in multicomponent systems. These characteristics can be achieved when the conditions shown in Table 2 are filled ${ }^{11)}$. Powders prepared by the sol-gel method using metal alkoxides can easily satisfy these requirements.

Table 2 Conditions required of starting powders for preparing high performance ceramics*

(a) Fine particles useful for high sinterability

(b) No formation of strong secondary particles

(c) Uniform particles size distribution for uniform pore or void size

(d) Particles of uniform composition corresponding to the bulk composition in multicomponent systems

* These conditions are easily satisfied when the sol-gel method is used.

\section{1 Fine particles without secondary particle formation}

Powders consisting of fine particles can be sintered to transparent glasses without pores or to dense, well-sintered ceramics at low temperatures. Low temperature sintering of a powder compact is very important. This is because heating at high temperatures may cause the undesirable decomposition of glasses or ceramics, the volatilization of components and the contamination of ceramics from furnace materials.

Fine particles have a large surface energy which promotes sintering of the powder compact. In order for this effect to be pronounced, particles have to be fine ((a) of Table 2) at less than $1 \mu \mathrm{m}$. If primary particles are too fine at less than, say, $20 \mathrm{~nm}$, however, larger secondary particles tend to be formed ((b) in Table 2) in which primary particles are tightly bonded together, and large pores are often found. Accordingly, it is desirable that the particle size should range between $20 \mathrm{~nm}-1 \mu \mathrm{m}$. It is known that the sol-gel method using metal alkoxide makes it possible to produce particles of such sizes.

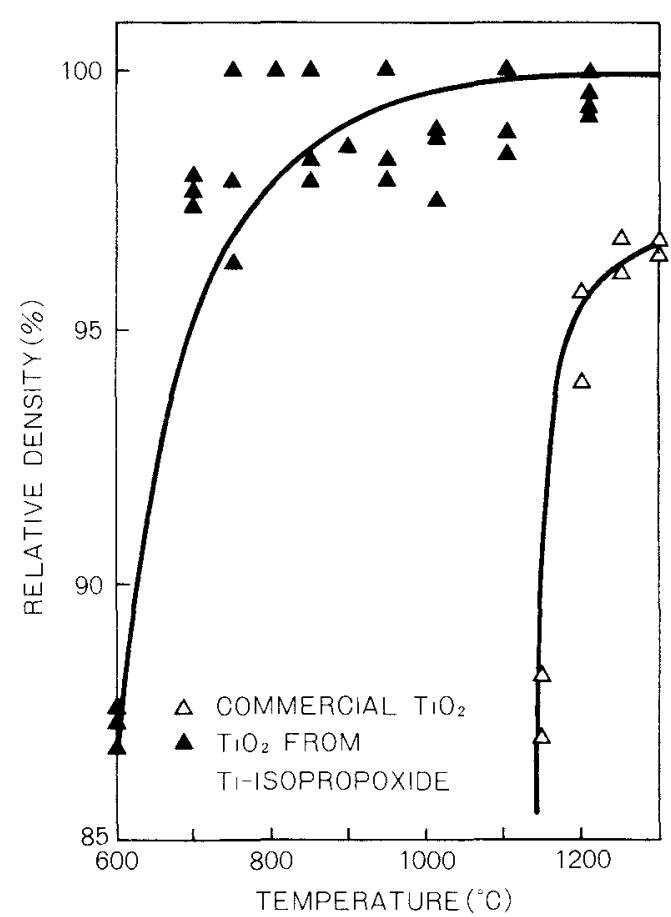

Fig. 2 Relative density vs. sintering temperature for $\mathrm{TiO}_{2}$ sample prepared by the hydrolysis of titanium isopropoxide. Sintered in $\mathrm{O}_{2}$ for 2 h. After L. Springer and M.F. Yan (Ref. 12) 
$W^{W}$ Springer and $\mathrm{Yan}^{12)}$ showed that $\mathrm{TiO}_{2}$ powder compacts made from titanium alkoxides, such as $\mathrm{Ti}\left(\mathrm{OC}_{2} \mathrm{H}_{5}\right)_{4}, \mathrm{Ti}\left(\mathrm{i}-\mathrm{OC}_{3} \mathrm{H}_{7}\right)_{4}$ and $\mathrm{Ti}\left(\mathrm{OC}_{4} \mathrm{H}_{9}\right)_{4}$, by the sol-gel method can be sintered at much lower temperatures than the compacts of commercial $\mathrm{TiO}_{2}$ powders, as shown in Fig. 2. An alcoholic solution of titanium alkoxide was sprayed into water through an orifice having a small nozzle for hydrolysis. Titanium hydroxide powder consisting of particles of $20 \sim 60 \mathrm{~nm}$ in diameter were formed and heated for $2 \mathrm{~h}$ at temperatures between $600 \sim 1200^{\circ} \mathrm{C}$. Figure 2 shows that powder compacts derived from a metal alkoxide are sintered to $99 \%$ of the theoretical density at temperatures lower than $900^{\circ} \mathrm{C}$, whereas the commercial powder needs temperatures higher than $1230^{\circ} \mathrm{C}$ for densifi-

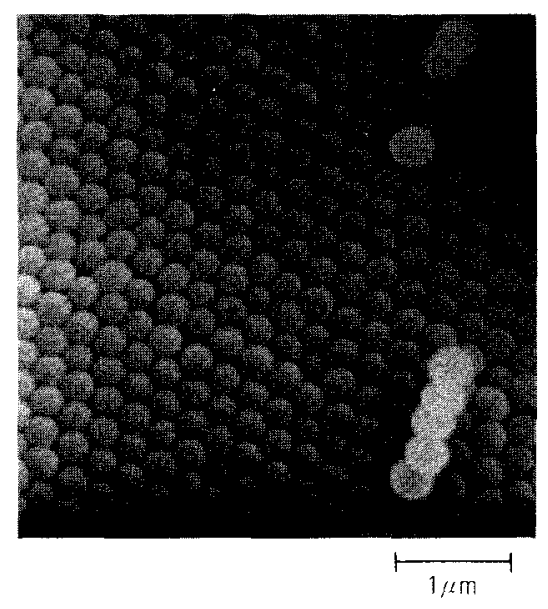

After heating at $1000^{\circ} \mathrm{O}$

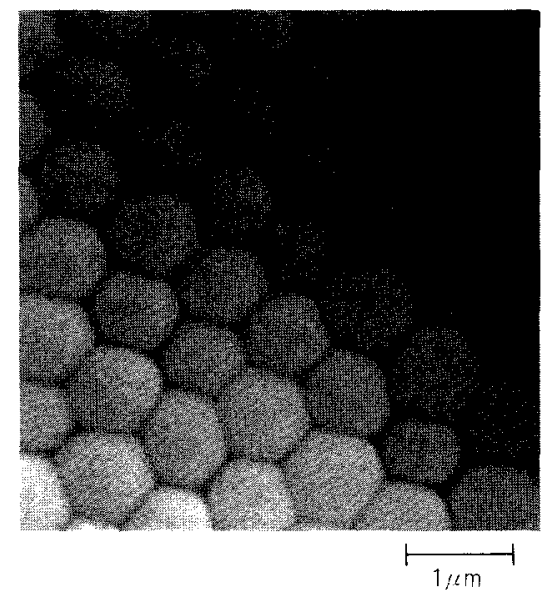

After heating at $1000^{\circ} \mathrm{C}$

(a) (111)plane is exposed cation to $96 \%$ of the theoretical density.

The possibility of obtaining well-sintered ceramics in the sol-gel method at temperatures $300 \sim 400^{\circ} \mathrm{C}$ lower than in conventional methods has been confirmed in the preparation of $\mathrm{BaTiO}_{3}$ ceramics ${ }^{13)}$ from $\mathrm{Ba}\left(\mathrm{OC}_{3} \mathrm{H}_{7}\right)_{2}$ and $\mathrm{Ti}\left(\mathrm{OC}_{3} \mathrm{H}_{7}\right)_{4}$, PLZT ceramics $\left.{ }^{14}\right)$ from $\mathrm{Pb}\left(\mathrm{OC}_{5} \mathrm{H}_{11}\right)_{2}$, $\mathrm{La}\left(\mathrm{OC}_{3} \mathrm{H}_{11}\right)_{3}, \mathrm{Zr}\left(\mathrm{OC}_{5} \mathrm{H}_{11}\right)_{4}$ and $\mathrm{Ti}\left(\mathrm{OC}_{5} \mathrm{H}_{11}\right)_{4}$, $\mathrm{Y}_{2} \mathrm{O}_{3}$-stabilized $\mathrm{ZrO}_{2}$ ceramics $^{15)}$ from zirconium and yttrium alkoxides and $\mathrm{SiO}_{2}$ glass ${ }^{16}$ ) from tetraalkoxysilanes.

\section{2 Uniform particle size distribution}

Monosized powders are useful as materials for ceramics, because it is possible to produce densely packed green bodies with monosized powders. Such bodies can be sintered to fine-

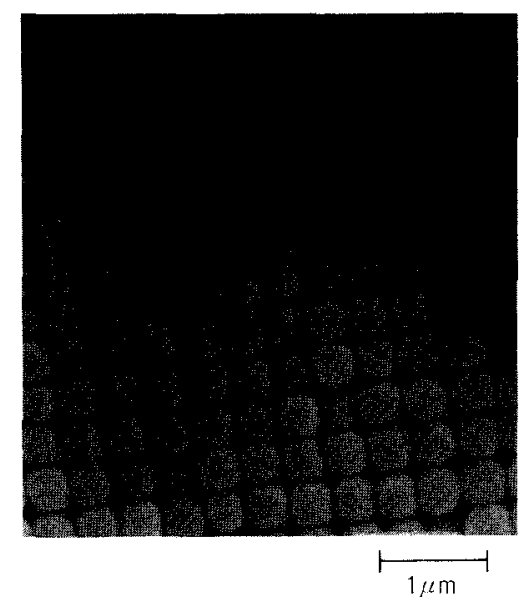

Before neating

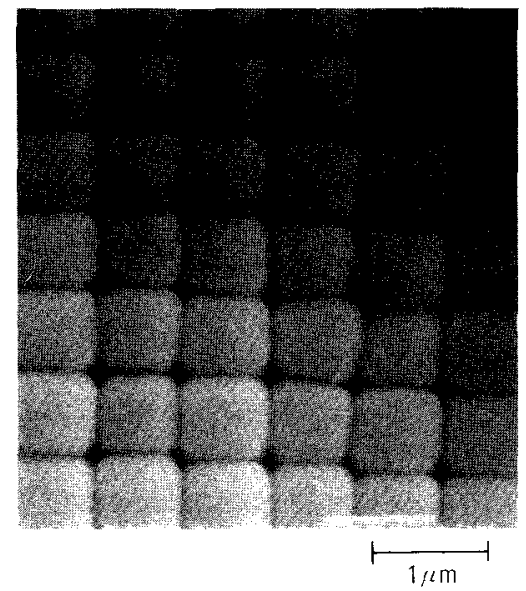

After heating at $1000^{\circ} \mathrm{C}$

(b) (100)plane is exposed

Fig. 3 Arrays of monosized $\mathrm{SiO}_{2}$ particles prepared from a $\mathrm{Si}\left(\mathrm{OC}_{2} \mathrm{H}_{5}\right)_{4}$ solution catalyzed with ammonia. $\mathrm{SiO}_{2}$ particles form face-centered cubic lattice ${ }^{22}$. 
grained dense ceramics of uniform grain size. No abnormal growth of grains takes place due to the monosize nature of particles, and dense sintering is possible due to uniform pore size distribution ((C) in Table 2).

It is important, however, to avoid agglomeration of primary particles to secondary large particles with large pores fixed in them. One method for avoiding agglomeration is to deposit monodispersed particles from the sol by shortening the distances between them in sol with the distances being kept uniform ${ }^{11)}$. Centrifugal deposition of particles on the bottom of the container or volatilization of the solvent can be used.

Monosized $\mathrm{SiO}_{2}$ particles ${ }^{17)}$ are prepared by hydrolyzing $\mathrm{Si}\left(\mathrm{OC}_{2} \mathrm{H}_{5}\right)_{4}$ in a $\mathrm{Si}\left(\mathrm{OC}_{2} \mathrm{H}_{5}\right)_{4}$ $\mathrm{C}_{2} \mathrm{H}_{5} \mathrm{OH}-\mathrm{H}_{2} \mathrm{O}$ solution catalyzed with $\mathrm{NH}_{3}$ in a controlled manner. Monosized particles of $\mathrm{TiO}_{2}{ }^{18,19)}$ and $\mathrm{ZrO}_{2}{ }^{19,20)}$ have also been prepared from $\mathrm{Ti}\left(\mathrm{OC}_{2} \mathrm{H}_{5}\right)_{4}$, and $\mathrm{Zr}\left(n \mathrm{OC}_{3} \mathrm{H}_{7}\right)_{4}$ or $\mathrm{Zr}\left(\mathrm{OC}_{4} \mathrm{H}_{9}\right)_{4}$, respectively.

When monosized spherical $\mathrm{SiO}_{2}$ particles are deposited on the test tube wall without agglomeration, particles are arranged in an ordered manner ${ }^{21)}$, if the condition for making deposition layers is appropriate. Disc-shaped pieces of dried $\mathrm{SiO}_{2}, 5 \sim 10 \mathrm{~mm}$ in length and width and $0.5 \sim 1 \mathrm{~mm}$ in thickness, show iridescence (rainbow-like color) under visible light due to diffraction of light. The ordered packing of $\mathrm{SiO}_{2}$ spheres can be seen in Fig. $3^{22)}$. Observation ${ }^{23)}$ of Kossel lines ${ }^{24)}$ produced by optical diffraction indicates that the particles are arranged in the face-centered cubic packing, forming a crystal of colloidal particles. It is interesting to note that hexagonally (a) and tetragonally (b) packed planes are seen in Fig. 3. These layers correspond to different particle surfaces of the face-centered cubic crystal.

\section{3 Uniform composition}

In order to have a ceramic which exhibits an aimed function, the composition must be uniform and identical through the multicomponent ceramic, that is, the composition must be the same for all the grains constituting the ceramic and also must be uniform within individual grains of ceramic ((d) of Fig. 1). This can be relatively easily achieved by the sol-gel method using metal alkoxides, because the solgel method starts from a homogeneous solu-

tion, and accordingly the oxide particles may have a uniform composition corresponding to that of the bulk.

Arai $^{25)}$ synthesized larger-structured aluminate ceramics of $\mathrm{BaO} \cdot 6 \mathrm{Al}_{2} \mathrm{O}_{3}$ which serves as support of the oxidation catalyst. It was found that the composition of the sintered body was identical in all the grains and was uniform within every grain when the starting powder is prepared by hydrolyzing barium and aluminum alkoxides in the solution containing both alkoxides. The sintering was done at $1600^{\circ} \mathrm{C}$.

It was also shown ${ }^{26)}$ that the so called "new mullite ceramic" consisting of only one phase exactly corresponding to the composition $3 \mathrm{Al}_{2} \mathrm{O}_{3} \cdot 2 \mathrm{SiO}_{2}$ can be made by using metal alkoxides. It should be mentioned that this mullite is very well sintered.

\section{Formation of shaped gels by the sol-gel method}

It this section, particle formation in sols for preparing shaped gels without passing through powder processing will be discussed based mainly on our work on silica.

\section{1 Particles for monolith formation}

For direct formation of monoliths, such as sheets, plates and rods, the formation of particles of suitable shape and size in sols is very important.

The major technological problems in the direct preparation of a silica gel monolith are the possible occurrence of cracks and fractures dur-

Table 3 Methods proposed for producing dried silica gel monoliths without crack formation ${ }^{4)}$

Method

(1) Drying under a supercritical condition

(2) Reaction of the solution with $\mathrm{pH}>7$ at a higher temperature

(3) Use of colloidal silica as the starting material

(4) Use of mixture of tetraethoxysilane and fine silica particles

(5) Use of a special solvent called a Drying Control Chemical Additive

(6) Use of high $\mathrm{HCl}$ solution
Investigator

Zarzycki et $a l^{9)}$

Yamane et $a l^{27}$, Susa $e t a l^{28)}$

Rabinovich et al ${ }^{29)}$, Scherer et al ${ }^{30)}$

Toki et al ${ }^{31)}$

Wallace and Hench ${ }^{32)}$, Adachi and Sakka ${ }^{33)}$

Kozuka and Sakka ${ }^{34)}$ 
int the process of a wet gel monolith to a dry gel monolith. The six methods shown in Table 3 have been proposed ${ }^{4)}$ to avoid cracks during drying, and they were actually used for producing silica gel monoliths without cracks. The basic principle common to the methods proposed is to lower the capillary force arising from the surface tension of the liquid in the drying gel. One of the potential ways to do this is to make particles large so that the pores might be large. The reciprocal proportionality of the capillary force to the pore diameter can be seen from the formula ${ }^{35), 36 \text {, }}$

$$
\Delta P=\frac{4 \gamma \cos \theta}{D}
$$

where $\Delta P$ is the capillary force, $\gamma$ is the surface tension of the liquid, $\theta$ is the contact angle, and $D$ is the capillary diameter corresponding to the pore diameter.

The authors used methods (5) and (6) to make two types of dried gel monoliths with $30 \sim 50 \mathrm{~nm}$ particles and $0.1 \sim 5 \mu \mathrm{m}$ particles, respectively. Particle sizes and their significances in making crack-free gel monoliths will be described next.

\section{1. 1 Silica gel monolith with particles of $30 \sim 50 \mathrm{~nm}$ in diameter}

Dried silica gel monoliths based on method (5) in Table 3 can be made from a solution containing an appropriate amount of ammonia ${ }^{33)}$. Figure 4 shows the particulate structure of a dried gel (a) and a sintered product obtained
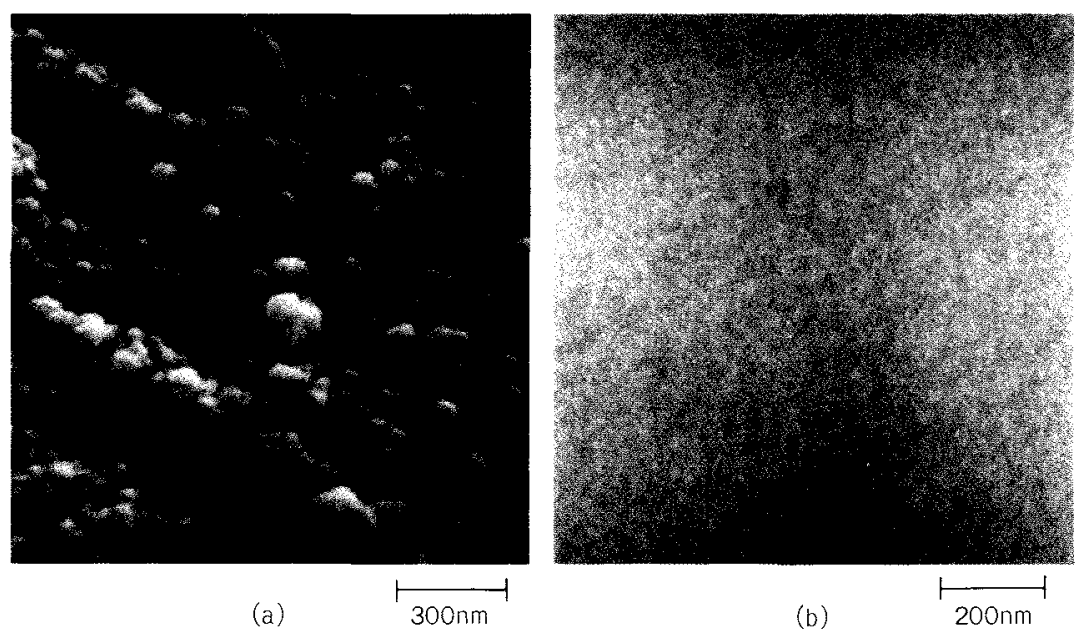

Fig. 4 SEM micrographs of the fractured surfaces of gels (a) dried at $150^{\circ} \mathrm{C}$ and (b) sintered for $2 \mathrm{~h}$ at $1050^{\circ} \mathrm{C}$, prepared from the solution 1TMOS : $1 \mathrm{DMF}: 2.2 \mathrm{CH}_{3} \mathrm{OH}: 10 \mathrm{H}_{2} \mathrm{O}: 3.7 \times 10^{-4} \mathrm{NH}_{4} \mathrm{OH}^{33)}$. by heating the gel to $1050^{\circ} \mathrm{C}(\mathrm{b})$.

In order to produce a dry gel monolith, a mixed solution of the composition $1 \mathrm{Si}\left(\mathrm{OCH}_{3}\right)_{4}$. $1\left(\mathrm{CH}_{3}\right) 2 \mathrm{NCHO} \cdot 2.2 \mathrm{CH}_{3} \mathrm{OH} \cdot 10 \mathrm{H}_{2} \mathrm{O} \cdot 3.7 \times$ $10^{-4} \mathrm{NH}_{4} \mathrm{OH}$ was reacted to gel at $30^{\circ} \mathrm{C}$ and aged by raising the temperature from $70^{\circ} \mathrm{C}$ to $160^{\circ} \mathrm{C}$ in $24 \mathrm{~h}$. The wet gel was then dried by raising the temperature from $70^{\circ} \mathrm{C}$ to $150^{\circ} \mathrm{C} \sim$ $160^{\circ} \mathrm{C}$.

The porous dry gel is particulate and porous as seen in (a) of Fig. 4. The size of particles ranges from 30 to $50 \mathrm{~nm}$, which gives continuous pores of $16 \mathrm{~nm}$ in average diameter. The formation of dried gel monoliths without cracks can be ascribed to the low surface tension of dimethylformamide which is retained at the final stage of drying of the wet gel, and to the considerably large pores due to large particles formed in the sol.

It should be noted, however, that the pore size is not uniquely determined by the particle size alone ${ }^{37,38)}$. The surface tension of the liquid filling the pores of the wet gels during drying may affect the pore size found after drying. The larger surface tension causes higher shrinkages of the pores because the pore walls consisting of particles undergo compressive stress arising from the capillary force based on the surface tension of the liquid. It has been found that the use of formamide in place of dimethylformamide in the starting solution gives smaller pores of $6 \sim 8 \mathrm{~nm}$ in diameter in the dried gel, although the particle size is similar to that in the gel prepared from a solution containing di- 



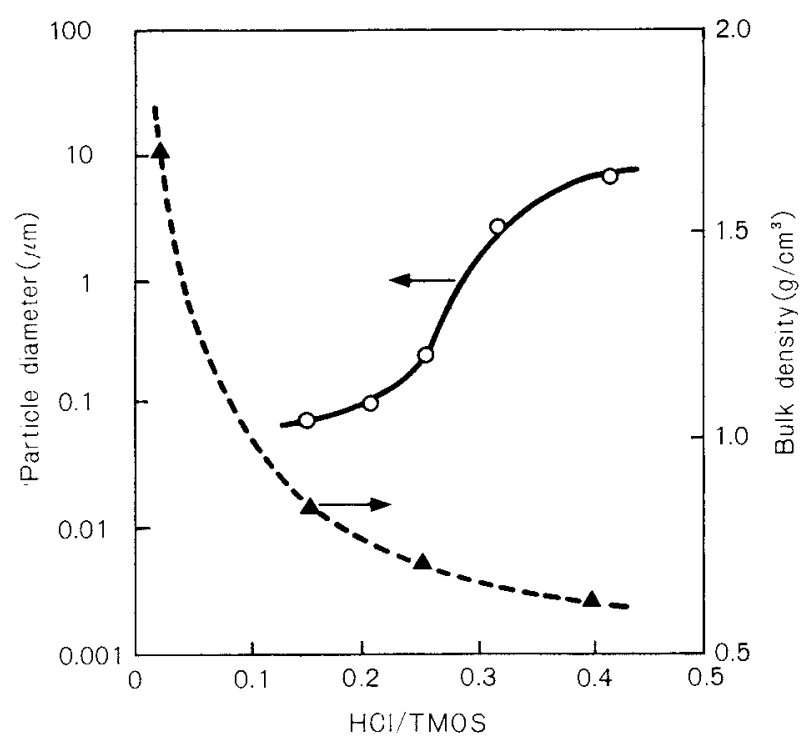

Fig. 6 Dependence of the particle size and the gel bulk density on $[\mathrm{HCl}] /[\mathrm{TMOS}]$ ratio for the solutions having a $\left.\left[\mathrm{H}_{2} \mathrm{O}\right] / \mathrm{TMOS}\right]$ ratio of 1.53 .

4. 1. 2 Silica gel monoliths with particles of $0.1 \mu \mathrm{m}$ to $5 \mu \mathrm{m}$ in diameter

Silica gel monoliths with very large particles of $0.1 \mu \mathrm{m}$ to $5 \mu \mathrm{m}$ in diameter can be made by the hydrolysis-polycondensation reaction of tetramethoxy-silanes in solutions of the system $\mathrm{Si}\left(\mathrm{OC}_{2} \mathrm{H}_{5}\right)_{4}-\mathrm{CH}_{3} \mathrm{OH}-\mathrm{H}_{2} \mathrm{O}-\mathrm{HCl}$ with very low concentrations of water and very high concentrations of $\mathrm{HCl}$. The compositions, appearances of gels and gelling times are shown in Table ${ }^{39}$, and some SEM photographs are shown in Fig. 5. Figure 6 shows the plots of the particle size and bulk density of a dried gel as a function of $[\mathrm{HCl}] /\left[\mathrm{Si}\left(\mathrm{OCH}_{3}\right)_{4}\right]$ ratio for the solutions with a constant $\left[\mathrm{H}_{2} \mathrm{O}\right] /[$ TMOS] ratio of 1.53 .

Figure 5 and 6 indicate that in the series of $\left[\mathrm{H}_{2} \mathrm{O}\right] /[\mathrm{TMOS}]=1.53$ (e to $\mathrm{k}$ in Table 1 ), solutions of high $\mathrm{HCl}$ contents at [HCl]/[TMOS] ratios equaling 0.15 through 0.40 give gels with a particulate structure, as seen in photographs $\mathrm{h}$ and $\mathrm{k}$ in Fig. 5, and that the particle size increases with increasing $\mathrm{HCl}$ content. In the gel prepared from a solution of $[\mathrm{HCl}] /[\mathrm{TMOS}]=$ 0.40 ( $\mathrm{k}$ in Fig. 5), round-shaped particles of about $5 \mu \mathrm{m}$ in diameter are connected to each other, forming $\mathrm{SiO}_{2}$ skeletons. The inspection of SEM micrographs indicates that the pore size in dried gels increases from $0.1 \mu \mathrm{m}$ for $[\mathrm{HCl}] /$ [TMOS] $=0.15$ to $10 \mu \mathrm{m}$ for $[\mathrm{HCl}] /[\mathrm{TMOS}]=$ 0.40 with increasing $\mathrm{HCl}$ content.

Since the pore size is large, the wet gels can be dried with no or almost no formation of cracks, as seen in Fig. 7. With the composition of $[\mathrm{HCL}] /[$ TOMS $]=0.40(\mathrm{k}$ in Table 4$)$, crackfree large place $(19 \mathrm{~cm} \times 23 \mathrm{~cm} \times 9 \mathrm{~mm})$ as shown in Fig. 8 can be made. It is interesting to see that crack formation is avoided when the pore size is large, and accordingly, the capillary force is small as seen from formula (4), although the liquid remaining at the final stage of drying may be water with a high surface tension.

The close inspection of the SEM micrographs

Table 4 Composition and properties of $\mathrm{Si}\left(\mathrm{OCH}_{3}\right)_{4}-\mathrm{CH}_{3} \mathrm{OH}-\mathrm{H}_{2} \mathrm{O}-\mathrm{HCl}$ solutions $\left.{ }^{39}\right)$

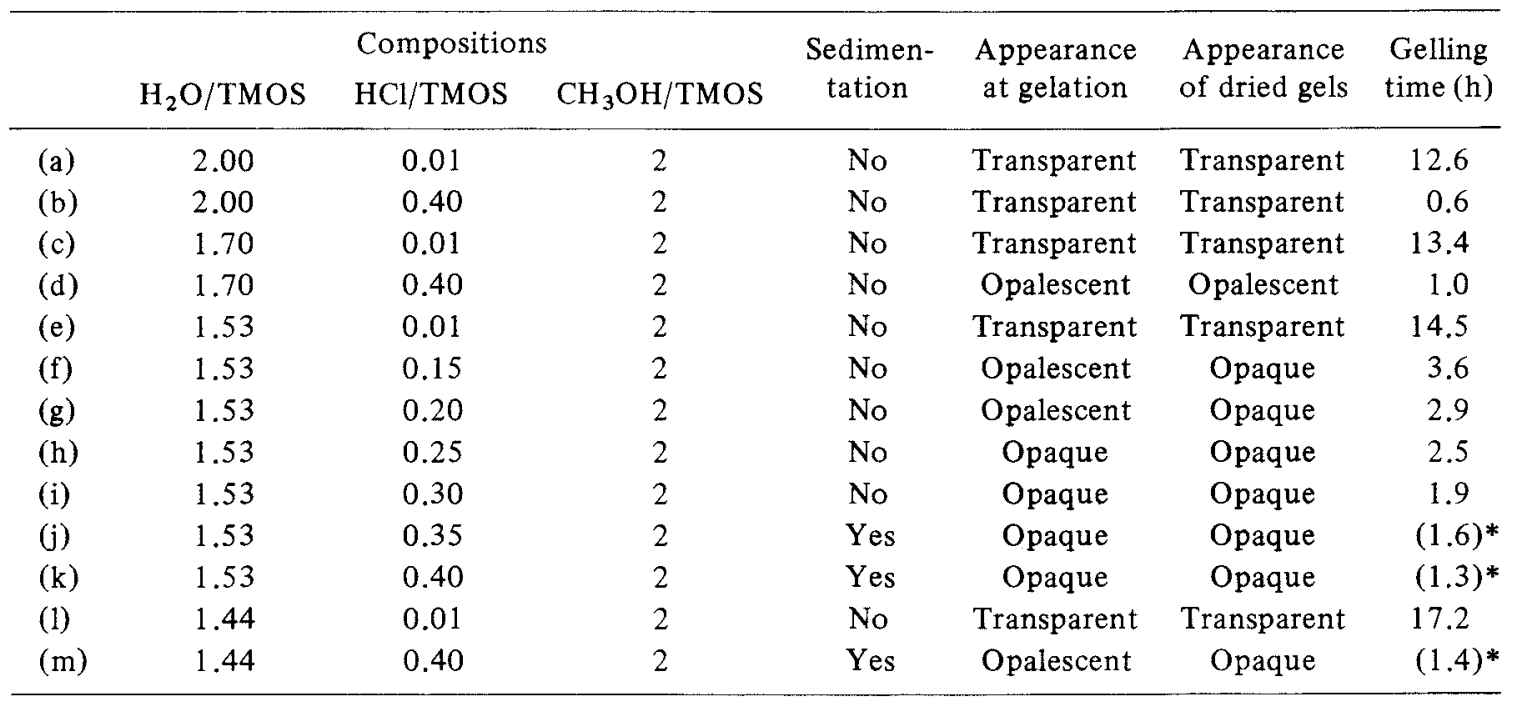

* No clear determination was made since gelation occurred during sedimentation. 


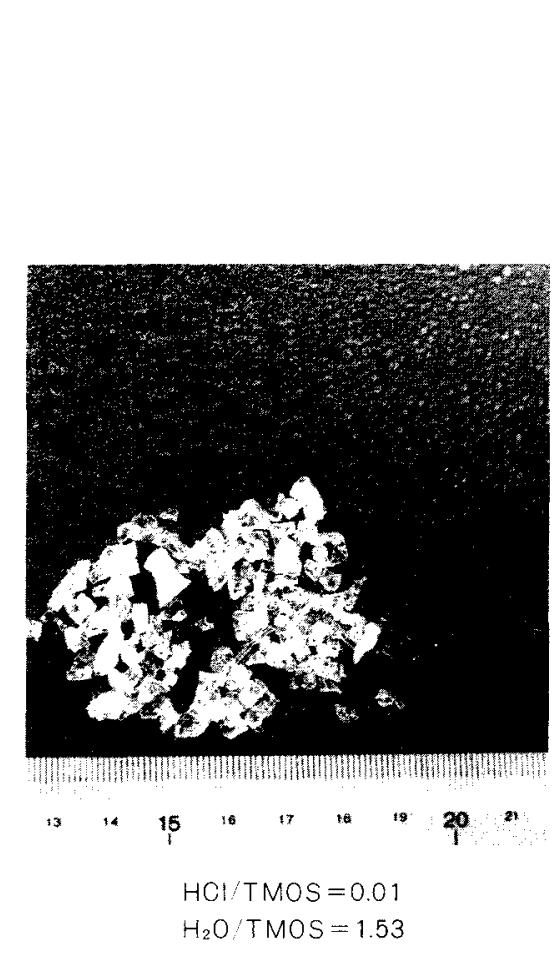

(e)

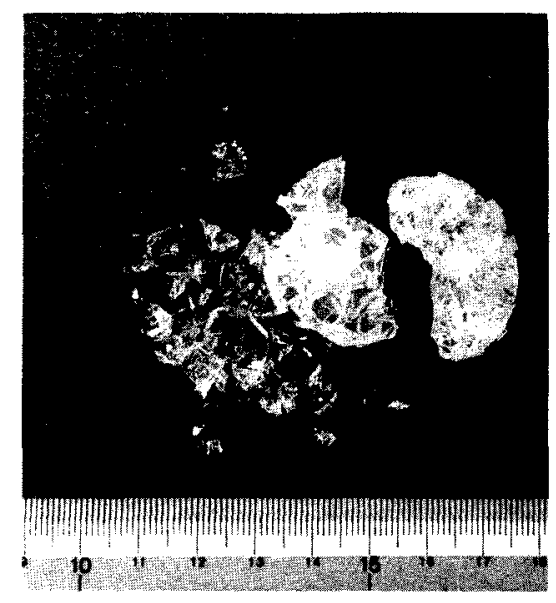

$$
\begin{aligned}
& \mathrm{HCl} / \mathrm{TMOS}=0.40 \\
& \mathrm{H}_{2} \mathrm{O} / \mathrm{TMOS}=2.00
\end{aligned}
$$

(b)

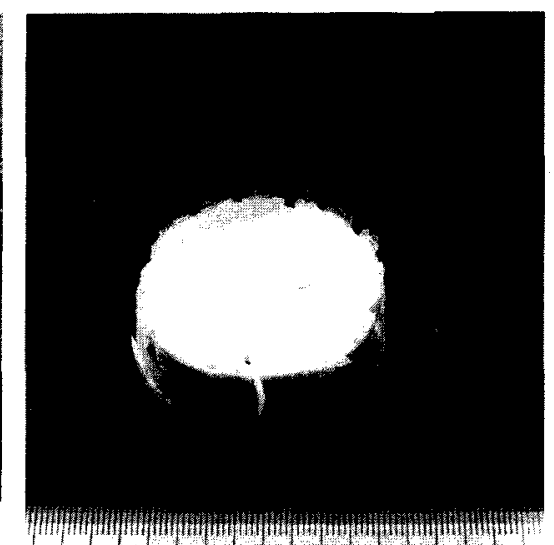

$$
\mathrm{HCl} / \mathrm{TMOS}=0.15
$$$$
\mathrm{HCl} \text { TMOS }=1.53
$$

(f)

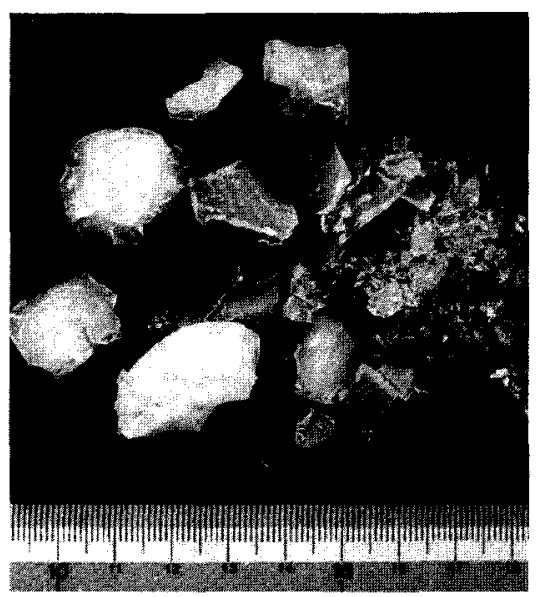

$$
\begin{aligned}
& \mathrm{HCl} / \mathrm{TMOS}=0.40 \\
& \mathrm{H}_{2} \mathrm{O} / \mathrm{TMOS}=1.70
\end{aligned}
$$

(d)

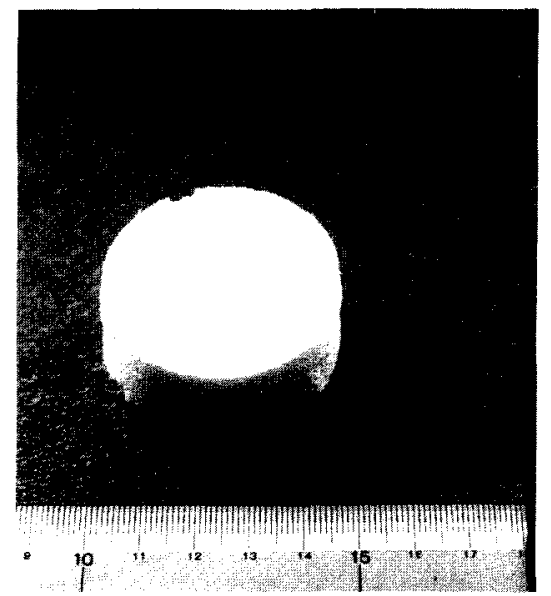

$\mathrm{HCl}$ : $\mathrm{TMOS}=0.40$ $\mathrm{H}_{2} \mathrm{O} / \mathrm{TMOS}=1.53$

(k)

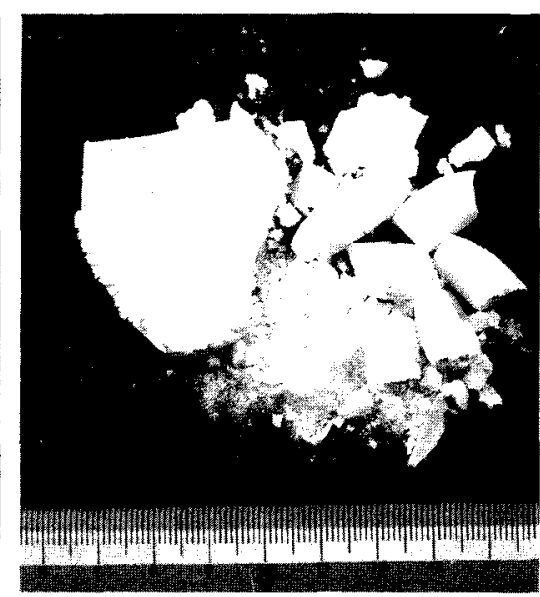

$\mathrm{HCl} / \mathrm{TMOS}=0.40$ $\mathrm{H}_{2} \mathrm{O} /$ TMOS $=1.44$

(m)

Fig. 7 Appearance of the dried gels. Constant $\left[\mathrm{H}_{2} \mathrm{O}\right] /[$ TMOS $]$ series $((\mathrm{e})$, (f) and $(\mathrm{k}))$ and constant [HCl]/[TMOS] series $((\mathrm{k}),(\mathrm{b}),(\mathrm{d})$ and $(\mathrm{m}))$. Symbols of pictures (e), (f) and so on correspond to those in Table 4.

of gels prepared from a solution with $[\mathrm{HCl}] /$ [TOMS $]=1.53$ and $[\mathrm{HCl}] /[$ TMOS $]=0.40(\mathrm{k}$ in Table 5) shown in Fig. 9 indicates that large particles reaching $5 \mu \mathrm{m}$ in diameter are porous secondary particles consisting of much smaller primary particles ${ }^{40)}$. This is also indicated by high specific surface area of more than $150 \mathrm{~m}^{2} /$ $\mathrm{g}$, which cannot be explained, if it is assumed that the observed large round particles are nonporous. The porosity decreases with drying time, as seen from comparison of (a) with (b) in Fig. 9. The surface of large particles becomes smoother when the drying time is prolonged to

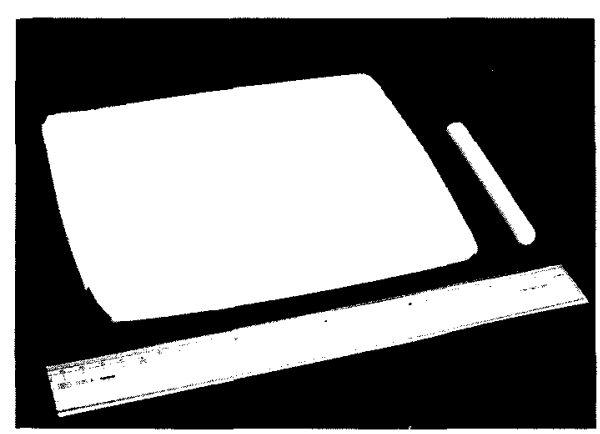

Fig. 8 A crack-free gel plate of $21 \mathrm{~cm} \times 17 \mathrm{~cm} \times$ $0.9 \mathrm{~cm}$ prepared from a TMOS solution of the composition, $\mathrm{TMOS}: \mathrm{H}_{2} \mathrm{O}: \mathrm{HCl}: \mathrm{CH}_{3} \mathrm{OH}=$ $1: 1.53: 0.25: 2$ in mole ( $\mathrm{g}$ in Table 4) 

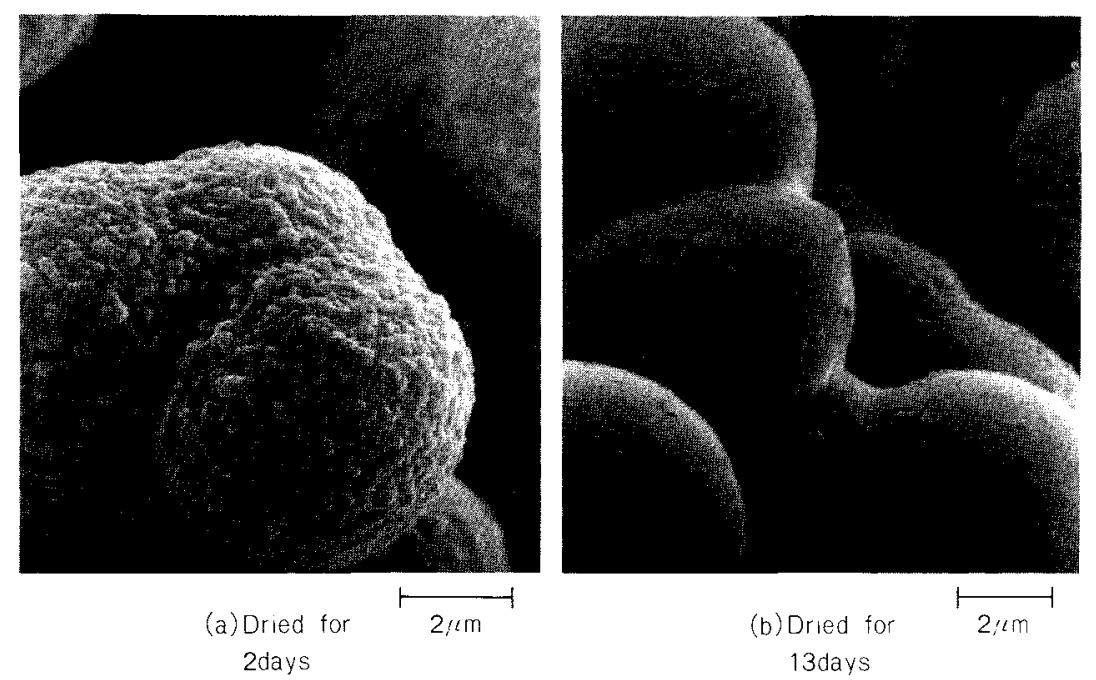

Fig. $9 \mathrm{SEM}$ micrographs of gels prepared from the solution with $\left[\mathrm{H}_{2} \mathrm{O}\right] /[\mathrm{TMOS}]=1.53$ and $[\mathrm{HCl}] /[\mathrm{TMOS}]=0.40$

13 days, although a pretty large surface area of $60 \mathrm{~m}^{2} / \mathrm{g}$ is still retained.

In the series of a constant $\mathrm{HCl}$ content at $[\mathrm{HCl}] /[\mathrm{TMOS}]=0.40$ to which pictures $\mathrm{k}, \mathrm{b}$, $\mathrm{d}, \mathrm{n}$ and $\mathrm{m}$ in Fig. 5 belong, the particulate structure can be seen for $\left[\mathrm{H}_{2} \mathrm{O}\right] /[$ TOMS] $<$ $1.50(\mathrm{k}, \mathrm{b}$ and $\mathrm{d})$, and the particle size increases with decreasing [HCl]/[TOMS] ratio. A still higher $\mathrm{H}_{2} \mathrm{O}$ content, however, leads to a higher degree of coagulation of particles, as seen from (n) in Fig. 5 and to the formation of closed pores in the matrix, as seen from (m) in Fig. 5. This structure is harmful to the formation of a crack-free dried gel monolith, because the vaporization of the solution in these closed pores causes the fracture of the gel during drying of the wet gel, as seen from Fig. 7 .

\section{2 Particles for fiber drawing from viscous gels}

For the direct sol-gel preparation of fibers, gel fibers are made by fiber-drawing from the viscous alkoxide solution at near room temperature $^{41), 42)}$. Figure 10 shows the time change of the viscosity $\left.{ }^{41}\right)$ of a drawable $\mathrm{Si}\left(\mathrm{OC}_{2} \mathrm{H}_{5}\right)_{4}$ $\mathrm{H}_{2} \mathrm{O}-\mathrm{C}_{2} \mathrm{H}_{5} \mathrm{OH}-\mathrm{HCl}$ solution with a mol ratio $r=[\mathrm{HCl}] /\left[\mathrm{Si}\left(\mathrm{OC}_{2} \mathrm{H}_{5}\right)_{4}\right]$ of 2 which is subjected to a hydrolysis-polycondensation reaction in a beaker having a cover perforated with a few small holes. When the viscosity reaches about 10 poises, the solution becomes spinnable, and fibers can be drawn by pulling a glass rod up from the sol or pulling the sol through an orifice.

It has been found that all starting solutions that become viscous in the gelation process do not necessarily exhibit spinnability. Only solutions with water contents lower than 4 in the $\left[\mathrm{H}_{2} \mathrm{O}\right] /\left[\mathrm{Si}\left(\mathrm{OC}_{2} \mathrm{H}_{5}\right)_{4}\right]$ ratio become spinnable when catalyzed with low concentrations of hydrochloric acid ${ }^{41)}$. The occurrence of spinnability has been ascribed to the shape of particles in sols. It has been assumed that only solutions containing long-shaped polymers or particles are spinnable, but solutions containing round-shaped particles or aggregates do not exhibit spinnability. This assumption has been confirmed to be valid by examining the relationship ${ }^{43)}$ between the reduced viscosity $\eta_{s p} / C$

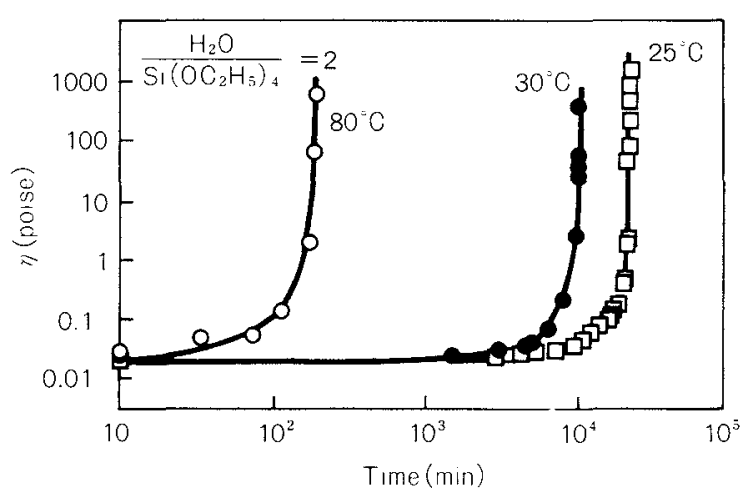

Fig. 10 Variation of the viscosity of a drawable $\mathrm{Si}\left(\mathrm{OC}_{2} \mathrm{H}_{5}\right)_{4}$ solution with the molar ratio $\mathrm{H}_{2} \mathrm{O} / \mathrm{Si}\left(\mathrm{OC}_{2} \mathrm{H}_{5}\right)_{4}=2$ at 25,30 and $80^{\circ} \mathrm{C}$ as a function of time 4,41 ) 


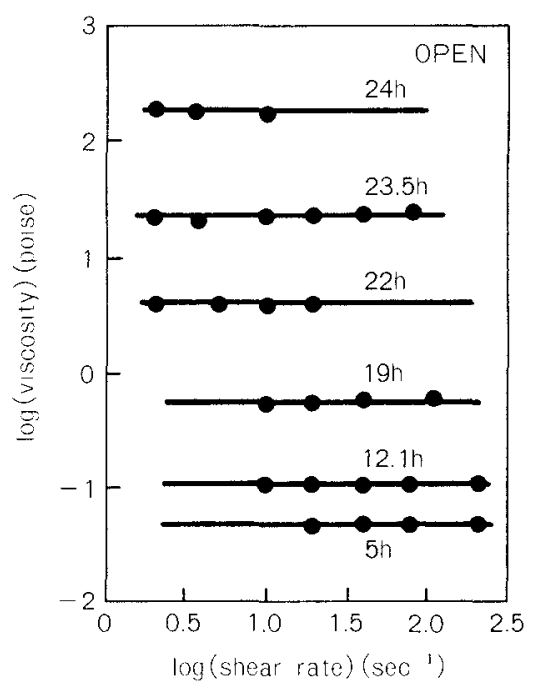

(a) Open system

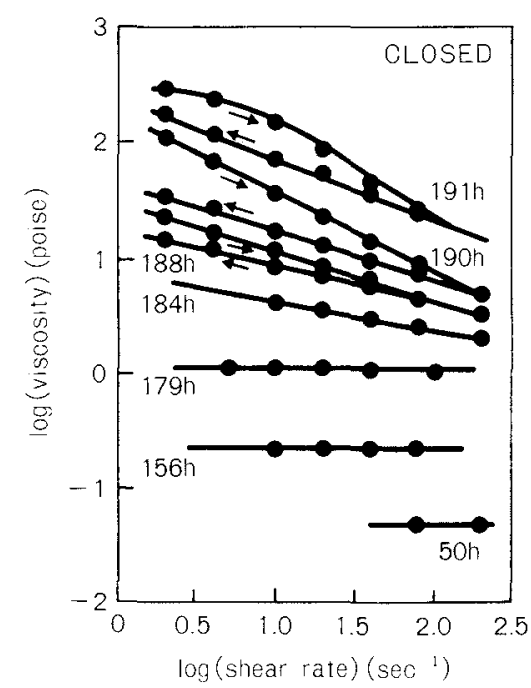

(b) Closed system

Fig. 11 Viscosity of $\mathrm{Si}\left(\mathrm{OC}_{2} \mathrm{H}_{5}\right)_{4}$ solutions at various shear rates in the open and closed systems ${ }^{42}$. Numbers shown in the figure denote reaction time of the solution. Reaction at $60^{\circ} \mathrm{C}$. Viscosity measurement at $30^{\circ} \mathrm{C}$.

and $\mathrm{SiO}_{2}$ concentration $C$, when $\eta_{s p}$ is the specific viscosity, and the relationship ${ }^{44)}$ between the intrinsic viscosity $[\eta]$ of the sol and the number-averaged molecular weight, $M_{n}$.

Recently, the occurrence of spinnability was correlated with the flow characteristics of the solution, as shown in Fig. 11. Figure 11 shows the viscosities versus shear-rate relationship for a tetraalkoxysilane solution of the composition $\mathrm{Si}\left(\mathrm{OC}_{2} \mathrm{H}_{5}\right)_{4}: \mathrm{H}_{2} \mathrm{O}: \mathrm{C}_{2} \mathrm{H}_{5} \mathrm{OH}: \mathrm{HCl}=1: 2: 1: 0.01$, which exhibits spinnability when subjected to the hydrolysis-polycondensation reaction in the open system. No spinnability occurs when reacted in the closed system. It is seen in Fig. 11 that the solution which is reacted in the open system and spinnable at viscosities higher than 10 poises retain Netwonian behavior (Fig. 11a) at high viscosities, whereas the non-spinnable solution reacted in the closed system becomes non-Newtonian (Fig. 11b) at high viscosities.

Figure 12 shows model structures which illustrate the change of structures of the solution during sol-to-gel transition. Figure 12(A) illustrates that linear (one-dimensional) long-shaped particles with less cross-linkages gives Newtonian nature and spinnability to viscous sols. This is because linear particles slip by each other without destruction under large shear rates even at high viscosities, and cross-linkings are formed between linear particles only after gelation. On the other hand, Fig. 12(B) indicates that in sols containing round particles, network-like clusters or secondary aggregates with loose bondings are constructed from primary round particles at high viscosities. This may cause shear thinning behavior and non-spinnability.

It is known that, in order to produce longshaped siloxane particles in the silicon alkoxide solutions, the starting solution should be catalyzed by acid, and the water content should be small. An ammonia catalyst and a high water concentration produce round-shaped particles.

\section{References}

1) Sakka, S.: The Science of the Sol-Gel Method, Agne-Shofu-Sha, Tokyo (1988) [in Japanese] .

2) Sakka, S.: Bull. Chem. Soc. Japan, 87 [3], 243 252 (1987) [in Japanese].

3) Sakka, S.: Treastise on Materials Science and Technology, 22, Glass III, ed. M. Tomozawa and R. Doremus, Academic Press, New York, p. 129-167, (1982).

4) Sakka, S.: Advances in the Fusion of Glass, ed. by D.F. Bickford et al., The American Ceramic Society, 2.1-2.27 (1988).

5) Sakka, S., K. Kamiya and T. Yoko: ACS Symposium Series, 360, Inorganic and Organometallic Polymers, ed. by M. Zeldin et al., American Chemical Society, Washington, D.C., p. 345-353 (1988).

6) Bradley, D.C., R.C. Mehrotra and D.P. Gaur, Metal Alkoxides, Academic Press (1978).

7) Mehrotra, R.C.: J. Non-Crystal. Solids, 100, 1-15, (1988). 


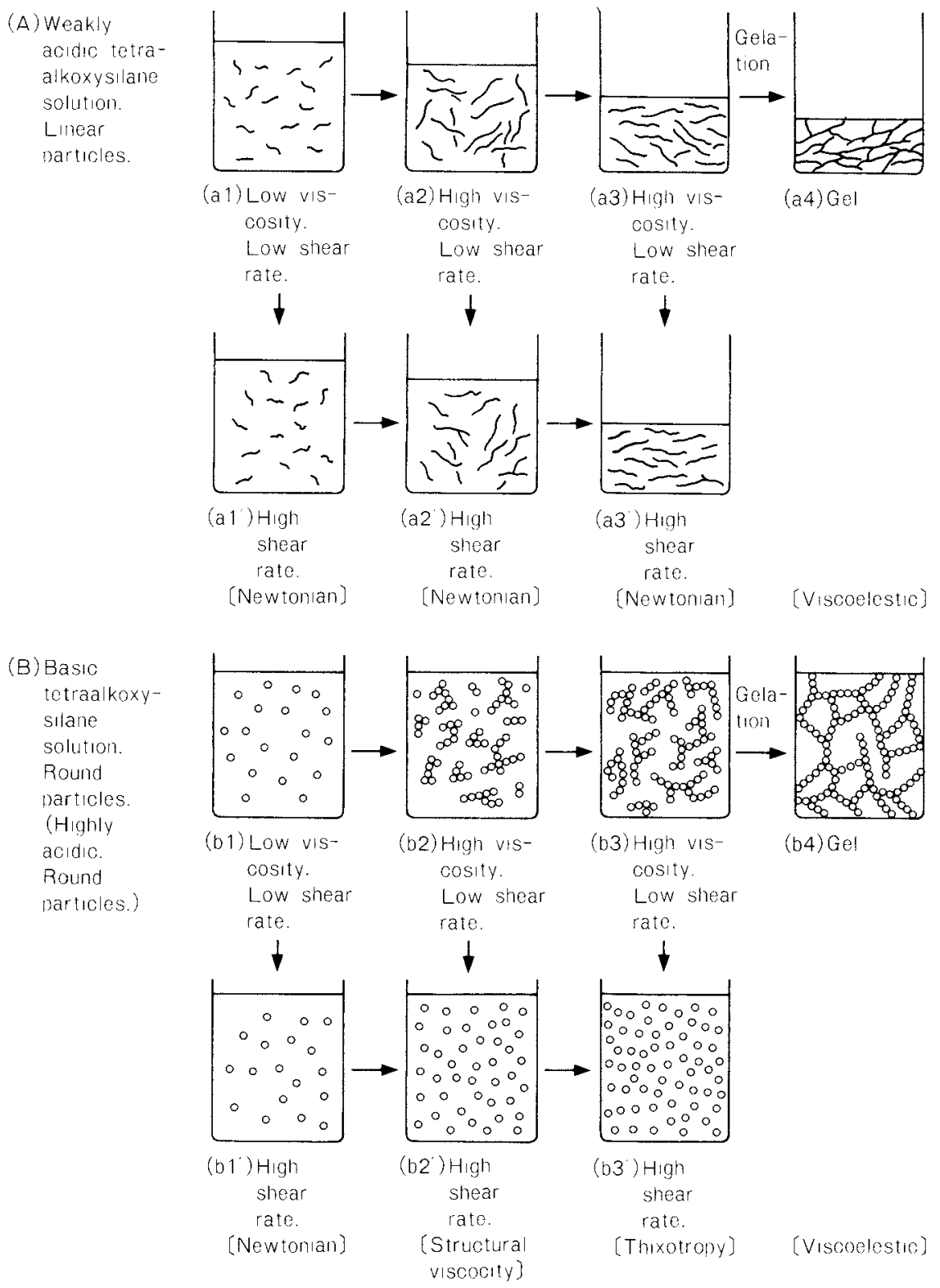

Fig. 12 Development of particles in solutions illustrating the changes in their rheological behavior in the sol-gel transition

8) Kamiya, K., T. Yoko and S. Sakka: Yogyo-KyokaiShi, 92, 242-249 (1984).

9) Zarzycki, J., M. Prassas and J. Phalippou: J. Mat. Sci., 17, 3371-3379 (1982).

10) Iler, R.K.: The Chemistry of Silica, John Wiley, New York (1979).

11) Barringer, E., N. Jubb, B. Fegley, R.L. Pober and H.K. Bowen: The Ultrastructure Processing of Glass, Ceramics and Composites, ed. L.L. Hench and D.R. Ulrich, John Wiley \& Sons, New York 315-333 (1984).

12) Springer, L. and M.F. Yan: Ultrastructure Processing of Glasses, Ceramics and Composites, ed. L. L. Hench and D.R. Ulrich, John Wiley \& Sons, New York, 464-475 (1984).
13) Mazdiyani, K.S., R.T. Dolloff and J.S. Smith: $J$. Amer. Ceram. Soc., 52, 523-526 (1969).

14) Brown, L.M. and K.S. Mazdiyasni: J. Amer. Ceram. Soc., 55, 541-544 (1972).

15) Phillipi, C.M. and K.S. Mazdiyasni: J. Amer. Ceram. Soc., 54, 254-258 (1971).

16) Decottignies, M., J. Phalippou and J. Zarzycki: $J$. Mater. Sci., 13, 2605-2608 (1978).

17) Shimohira, T. and N. Tomuro: Powder and Powder Metallurgy, 23, 249-254 (1976) [in Japanese] .

18) Ikemoto, T., K. Uematsu, N. Mizutani and M. Kato: Yogyo-Kyokai-Shi, 93, 261-266 (1985) [in Japanese].

19) Fegley, B and E.A. Barringer: Mat. Res. Soc. Symp. Proc., Vol.32, 187-196, (1984). 
20) Ikemoto, T., N. Mizushima, M. Kato and Y. Mitarai: Yogyo-Kyokai-Shi, 93, 585-586 (1985).

21) Onoda, G.Y.: The Science of Ceramic Chemical Processing, ed. by L.L. Hench and D.R. Ulrich, John Wiley \& Sons, 504-512 (1986).

22) Adachi, T., M. Okada and S. Sakka: Unpublished data.

23) Observation was made by Prof. T. Yoshiyama and I. Sogami of Kyoto Industrial University.

24) Yoshiyama, T., I. Sogami and N. Ise: Phys. Rev. Lett., 53, 2153-2156 (1984).

25) Arai, H.: ' 87 Arita International Symposium on Fine Ceramics, 88-113 (1987).

26) Pask, J.A., X.W. Zhang, A.P. Tomsia and B.E. Yoldas: J. Amer. Ceram. Soc., 70, 704-707(1987).

27) Yamane, M., S. Aso, S. Okano and T. Sakaino: $J$. Mat. Sci., 14, 607-611 (1979).

28) Susa, K., J. Matsuyama, S. Satoh and T. Suganuma: Elect. Lett., 18, 449-450 (1982).

29) Rabinovich, E.M., D.W. Johnson, J.B. McChesney and E.M. Vogel: J. Non-Crystal Solids, 63, 155 161 (1984).

30) Scherer, G.W. and J.C. Luong: J. Non-Crystal Solids, 63, 163-172 (1984).

31) Toki, M., S. Miyashita, T. Takeuchi, S. Kanbe and A. Kochi: J. Non-Crystal. Solids, 100, 479-482 (1988).

32) Wallace S. and L. L. Hench: Mat. Res. Soc. Symp. Proc., Vol. 32 (1984) 47-52.
33) Adachi T. and S. Sakka: J. Mat. Sci., 22, 4407. 4410 (1987).

34) Kozuka H. and S. Sakka: Chem. Lett., 1791-1794 (1987).

35) G.W. Scherer: Yogyo-Kyokai-Shi, 95, 21 (1987).

36) Zarzycki, J.: "Ultrastructure Processing of Ceramics, Glasses and Composites" ed. by L.L. Hench and D.R. Ulrich, John Wiley, New York, p. 37 (1984).

37. Adachi, T., S. Sakka and M. Okada: Yogyo-KyokaiShi, 95, 970-975 (1987).

38) Adachi T. and S. Sakka: J. Non-Crystal Solids, 99 , 118-128 (1988).

39) Kozuka, H. and S. Sakka: Chemistry of Materials, 1, 398-404 (1989).

40) Yamaguchi, J., H. Kozuka and S. Sakka: To be published in Proceedings, The 1st Meeting of the Society of New Functional Materials, S. Somiya and M. Doyama, Tokyo (March, 1989).

41) Sakka, S.: Mat. Res. Soc. Symp. Proc., Vol. 32, 91.99 (1984).

42) Sakka, S.: Rheology of Sols in the Sol-Gel Processing, to be published in Winter School on Glasses and Ceramics from Gels, August 1989, Sao Carlos, Brazil.

43) Sakka, S. and K. Kamiya: J. Non-Crystal Solids, 48, $31-46$ (1982).

44) Sakka, S., K. Kamiya, K. Makita and Y. Yamamoto: J. Non-Crystal Solids, 63, 223-235 (1984). 